\title{
Making Sense of Coach Development Worldwide During the COVID-19 Pandemic
}

\author{
Bettina Callary \\ Cape Breton \\ University
}

Pekka Clewer

Haaga-Helia University

of Applied Sciences

\author{
Abbe Brady \\ St Mary's University
}

Rui Resende

Instituto Universitário

da Maia

\author{
Cameron Kiosoglous \\ USRowing and \\ Drexel University
}

Tammy Mehrtens

Netball New Zealand

Rita Horvath

Hungarian Coaching

Association

\begin{abstract}
The commentary brings together the perspectives of a group of coach developers from across the globe who form a community of practice (CoP) from their involvement as "Cohort 5" in the International Council for Coaching Excellence and Nippon Sport Science University Coach Developer Academy. The CoP includes people from three types of organizations: university professors of sport coaching programs, national sport federations, and national multisport organizations' directors of coach education. While this CoP existed prior to the pandemic, the forced isolation has created a new structure and purpose to the CoP: The authors are all making meaning of the landscape of coach development within which they work by understanding the perspectives of others who work in their domain from across the world and the similar realities that they face in North America, Europe, the United Kingdom, and New Zealand. The authors outline the key themes that emerged from their weekly CoP video conference meetings to shed light on how this pandemic has changed the way they think about coach development.
\end{abstract}

Keywords: coach developer, community of practice, education, online meetings

\footnotetext{
Callary is with Cape Breton University, Sydney, NS, Canada. Brady is with St Mary's University, Twickenham, United Kingdom. Kiosoglous is with USRowing, Princeton, NJ, USA, and Drexel University, Philadelphia, PA, USA. Clewer is with the Haaga-Helia University of Applied Sciences, Vierumäki, Finland. Resende is with the Instituto Universitário da Maia, Castelo da Maia, Portugal. Mehrtens is with Netball New Zealand, Christchurch, New Zealand. Wilkie is with the Irish Rugby Football Union, Dublin, Ireland. Horvath is with the Hungarian Coaching Association, Budapest, Hungary. Callary (bettina_callary@cbu.ca) is corresponding author.
} 
Coach developers (CDs) are individuals who develop, support, and challenge coaches in their ongoing efforts to improve knowledge and skills for athletes; thus, CDs have an impact on positive and effective quality sport experiences (International Council for Coaching Excellence, 2014). The Nippon Sport Science University Coach Developer Academy (NCDA) "was established to foster future international Coach Developers and to construct a network of coach developers all over the world" (Nippon Sport Science University, 2020, para. 1). This program, organized by the Nippon Sport Science University and the International Council for Coaching Excellence, was established in 2014 through a Japanese government grant leading up to the 2020 Olympic Games (Nippon Sport Science University, 2018). Since its inception, the NCDA has seen six 1-year cohorts pass through the program. This includes over 60 participants from over 27 countries who applied and were chosen based on their involvement in coach development either as a university professor involved in coach development, a National Sport Federation, or a National Multisport Organization director of coach education (Nippon Sport Science University, 2018).

For each cohort, once chosen, the participants were given precourse online modules to complete at home (in June), in which they did not meet the other participants. They then participated in a 1-week residential program in Japan (in July), in which they lived together in a "guest house," went to classes at the university, and engaged in cultural activities. Between July and February, the participants completed assignments and applied what they had learned in the residential program, including meeting with trainers and subgroups from the cohort via video conferencing. In February, all participants returned to Japan for a second 1-week residential program that included classes, a conference, cultural activities, and a graduation ceremony (Nippon Sport Science University, 2018). All participants from all cohorts were invited to join a private Facebook group called the "NCDA family," and, due to the close nature of the residential camps and the identical living arrangements for each cohort, many participants across the cohorts came to know and instantly connected with one another at subsequent conferences or other gatherings.

In this commentary, we, eight members of the NCDA's Cohort 5, have provided the takeaway messages from our shared dialogues regarding coach development during the COVID-19 pandemic, which has seen everyone around the world involved in coach development required to work from home, in online modes. While we had a preexisting close connection to one another, since the end of our program in February 2019, we have maintained intermittent contact via WhatsApp group texts, we organized two group Zoom calls, and some have visited one another, if work-travel opportunities arose. Much like an extended family, we maintained a tight connection despite more sporadic meetings.

In March 2020, when, around the world, we went into lockdown, we organized a group online meeting. After the first Zoom call, we determined that we would like to make these weekly meetings. We liken our group to a community of practice (CoP), which is a group of people "who share a concern, a set of problems, or a passion about a topic, and who deepen their knowledge and expertise in this area by interacting on an ongoing basis" (Wenger, McDermott, \& Snyder, 2002, p. 4). More recently, Wenger-Trayner and Wenger-Trayner (2015) have noted that there is no one place that can contain all the information about a 
practice. Indeed, they suggested that complex social systems interlock with each other in knowledge formation and called such systems landscapes of practice, which are composed of the intersection of many different CoPs and other social learning systems (i.e., networks). We see our CoP fitting into the Landscapes of Practice (LoP) for CDs globally and understand that the knowledge we bring from our own various learning systems (such as research-based networks and practitioner CoPs) all relate and bring focus to our meetings. Thus, we each make meaning during the pandemic of the landscape of coach development within which we work by understanding the perspectives of our fellow Cohort $5 \mathrm{CoP}$ members from across the world who are living out similar professional realities.

We will begin by introducing each of our contexts: the first five authors (B. Callary, A. Brady, C. Kiosoglous, P. Clewer, and R. Resende) are university professors in Canada, the United Kingdom, the United States, Finland, and Portugal respectively, whose main involvement in coach education is through teaching student-coaches in their programs, as well as engaging in coach development research. The next two authors (T. Mehrtens and M. Wilkie), along with C. Kiosoglous listed previously, have the following titles: National Training Manager-Coach Development, at Netball New Zealand; Head of Coach Development at Irish Rugby Football Union; and US Rowing's National Team Sports Science Coordinator and Coaching Development Consultant. Finally, the eighth author (R. Horvath) is a consultant for the Hungarian Coaching Association, which is a multisport organization, and organizes coach development programs for elite, development, and youth coaches.

The pandemic has changed our jobs: We have moved to online delivery of coach education, whether that is through sport-specific modules within the National Sport Federation, multisport courses and programs in the National Multisport Organization, or higher education courses in universities. The switch to online learning has not been entirely new: Over the past 15 years, coaching organizations have increasingly turned to online self-paced course delivery, which has the benefits of having extensive reach and contextual validity of learning videos (Driska \& Nalepa, 2020). However, technological issues, such as the usability of and accessibility to online platforms need to be further considered. Pedagogically, what coach education worldwide has in common is a focus on experiential learning using a LEARNS framework (Walters, Rogers, \& Oldham, 2020). This framework is an acronym based on coach education that is (a) Learnercentered, where learners are (b) Engaged, in which people are given the opportunity to (c) Apply their knowledge and skills, which includes (d) Reflection, while drawing out (e) New knowledge through challenging coaches to feel (f) Stretched, or helping them to grow (Walters et al., 2020). A focus on LEARNS is difficult in isolation. Nonetheless, in an effort to be more learner-centered, coach education has increasingly looked at developing the coach as a person and, in turn, encouraging the coach to care for the athlete as a person first (Dohsten, BarkerRuchti, \& Lindgren, 2020). In turn, research is now emerging about how coaches can support athlete mental health (Bissett, Kroshus, \& Hebard, 2020), and sports federations, too, are now beginning to launch coach education specifically around mental health (e.g., Scottish Football Association, 2020).

Our commentary documents how we have responded to a world crisis within our segment of the sport system and speaks to the challenge and opportunities of 
working through our new job contexts, the ideas that came from our CoP weekly meetings, and the support we provided to one another. Sharing this commentary is important, as practitioners and researchers alike are trying to determine how the pandemic has changed and will continue to change the structure, pedagogy, and approach to coach development. Around the world, we are hearing the same questions for which answers are sought. Thus, our commentary, built from different angles of the same issue, outlines the themes arising from our responses to the following three questions: The respective answers to the questions that we asked ourselves overlapped, and so we present themes that share our collective understanding from across the globe on how we are making meaning of coach development in light of COVID-19. Drawing upon our expertise in qualitative research, we were guided by the processes of thematic analysis to identify key themes in our responses (see Braun \& Clark, 2006). The first author compiled our responses to review our collective responses. The first author then coded sections of text into meaning units, suggesting themes that could be seen across the codes. All authors were then invited to review the themes and provide input. The second and third authors then collated the codes and merged similar themes, selecting which meaning units to include verbatim in the write-up to create a unified commentary. All authors were again invited to review and provide input. The resultant five themes are presented below.

a. How has the pandemic affected the way you deliver coach education?

b. What do you think are the three most pressing issues for your job during this pandemic, and how can we deal with these issues?

c. What does the NCDA Cohort 5 CoP do for you?

\section{Key Themes: Changing Demands for CDs}

Working online and from home to support coaches, who in turn, are working online to support athlete/team development, created significant new challenges, such as a need to rapidly learn how to use online learning systems and to create high-quality instruction online. Furthermore, we began to see the importance of caring and supporting coaches holistically, which includes an increased availability of online learning opportunities. We also noted that practitioners and researchers are supporting one another more readily, with new areas of support emerging that are directly associated with new challenges facing coaches and athletes under lockdown. An unusual mirroring across the sports sector is that everyone still working is facing challenges associated with balancing demanding new work issues and maintaining time for personal and family life.

\section{Transition to Online Platforms}

The COVID-19 pandemic highlighted the value of access to existing online learning systems. Most CDs had online systems in place, but they were not being fully utilized. Needing to go completely online, institutions of higher education appeared to have the advantage. B. Callary and R. Resende, both professors, highlighted that it "has not been a difficult transition." However, the move online 
presented new challenges for coaches who do not find it easy studying online. R. Resende identified that an unresolved challenge during this lockdown period is "not being able to see coaches in practice." Indeed, many CDs are looking to better understand coaches' experiences of online learning to be able to support them more effectively. There are also the challenges for everyone working from home, "especially the juggling act of the various roles we each are managing," as touched on by C. Kiosoglous. But there is a positive feeling that this transition to online delivery will be useful for coaching education after the pandemic. CDs are looking at new initiatives and more versatile methods and tools to deliver coach education online. M. Wilkie, from Irish Rugby, noted that, as CDs, "we are adapting our practices of supporting coaches by modernizing and evaluating our online offerings." With an eye right now on next steps, A. Brady indicated "the way we approach planning is going to be the key to meeting the unknown needs of future online coaching education programs."

High-Quality Instruction Strategies Online. The pandemic has certainly put a halt to many activities in the sport as we know it. While B. Callary mentioned that "some participatory action research cannot continue at this time," novel ideas around innovating coaching and coach education are emerging as important subjects to research, such as high-quality instructional strategies for online delivery and remote coaching. These ideas have been cultivated from webinars and online meetings from leaders from around the world. This is an example of how different CoPs are sharing information across the wider LoP for CDs, which is sharing information directly across the landscape worldwide. As an example of implementation from shared collaboration in our CoP, T. Mehrtens at Netball NZ shared examples of direct benefits, such as "new online tools that were shared, including feedback on how we developed the LEARNS principles for online course delivery, advice on topics for our online coaches series, and key aspects of consideration for the prospect of 'return to sport."'

\section{Care and Support}

The CDs from around the world have seen a shift in their roles, from focusing on delivery content and best practices to connecting online to show care and support for the well-being of coaches and athletes in their respective situations. They are concerned about their own health and the health of those around them, in addition to the related hardships of lost income and the general uncertainty of this situation. T. Mehrtens shared how CDs have been "connecting with trusted colleagues" who understand respective contexts with a view of increased empathy. This connection through our CoP and others in our LoP has also created interest for CDs to think about how the future of virtual connections might look once we return to a new normal.

Holistic Development and the Well-Being of Coaches. The universality and pervasiveness of our present working conditions has created many shared challenges, and we have witnessed how professional conversations and activities among coaches and CDs have embraced a more personal, as well as professional, agenda. A concern for the holistic development and well-being of coaches (and, in turn, athletes) has become more evident in our work. Coaches, too, will be 
supporting athletes beyond their usual role remit at present. As R. Resende highlighted, helping athletes now will require coaches to understand how to support athlete development beyond sports skills, and we need to "put the athlete at the center of learning to achieve this goal." Considering the challenges many coaches and athletes are experiencing, B. Callary noted, "coaches' understanding of their own and their athletes' mental health needs better educational initiatives." This is a direct call for us as CDs to extend our remit.

Personal Impacts of Increased Availability of Online Learning Opportunities A feature of the transition to online learning is the increasing accessibility of webinars for coaches. While many of these focus on valuable technical and pedagogical domains, as CDs, an explicit part of our role is also the need to focus on interpersonal and intrapersonal skills. This point was reinforced in our own experiences of supporting each other within our $\mathrm{CoP}$, as we shared not only our professional knowledge, but also our everyday stresses and pressures. As B. Callary observed,

We can use the "wild west" of webinars currently being developed by so many sport organizations that provide unprecedented (and often free) access to world leaders in any domain. This access gives us professional knowledge for coaching. However, we also need to turn to strategies that hone coaches' interpersonal skills and their reflexiveness and self-awareness of their own behaviors, thoughts, and feelings.

\section{Support of Other Systems}

P. Clewer explained that CDs in higher education have been able to "support federations who don't have the technology" and systems already in place. R. Horvath countered that her national multisport organization has also been able to support institutions that do not have online expertise. Supporting coaches across all systems to have high-quality online education has been another positive outcome of the pandemic. For example, in Hungary, there have been efforts to help physical education teachers who need to provide online homeschool lessons to children. However, given the large number of coaches who may have limited access and expertise in using technology, this requires much further work and research to know how to best support all coaches.

Apart from technological concerns, a specific area raised is how, as CDs, we support coaches to be ready for a "return to play." There are different challenges, which vary according to the contexts, such as participation, youth development, and performance coaching. As T. Mehrtens noted, for many participation and youth coaches, a challenge will be "generating engagement for our sport again" and supporting coaches' "ability to create excitement and motivation within their teams, to build the desire for everyone to return. We are currently working on a number of resources and promotional avenues to ensure coaches have everything they need to do this." As R. Horvath acknowledged, the role of sport in society has now already significantly changed and, despite the ongoing uncertainty, "until we return to the normal and usual lifestyle, we should all be positive, progressive, and looking forward." Nonetheless, M. Wilkie questioned what sport would look like, 
prompting B. Callary to reflect on the pandemic shifting children's physical activities to home-based unstructured play. She suggested that the management of youth sport, in particular, will need to be scrutinized. Parents, who are often volunteer coaches or helpers in some other capacity, may be realizing that the ideal of having children engage in multisport was coming at considerable expenses to their home-life balance. She thus wondered about the position of CDs in the future, questioning the length of sport seasons, the number of competitions and training hours, and the capitalist priorities of some youth sports.

\section{Job Insecurity}

The theme of job insecurity captures the ongoing and varied tensions for professional coaches through to sessional paid community coaches, relating to whether and if to return and how, after lockdown, their sports coaching work will resume. Anticipating a significant economic downturn in most countries' gross domestic product, fears about how the sports industry will be affected financially are rife among coaches and CDs. As M. Wilkie commented in relation to professional club settings, "certain staff populations were furloughed (not allowed to work) or on reduced working hours as a result of the pandemic." The return to sport in professional settings will, for many sports, depend on financial decisions, whereas, for community sports, it may be based largely on a volunteer coaching workforce. In many sports, the financial impact of the pandemic has already been felt. T. Mehrtens described how, in New Zealand,

The Netball system has already lost staff across the country, and there is a fear that the full force of this has not yet been felt. Job insecurity is therefore a major concern at the forefront of everyone's minds. The capacity to deliver coach education will almost certainly be reduced. Plans for support and resource development for 2020 will have to change or be stopped completely, to fit within the new financial environment.

Concerns about financial instability and job insecurity within the sports industry will have pervasive, though varied, impacts on different organizations' coach development programming. For those in universities, increasing job insecurity in sport and specifically among coaches has a number of byproducts. A. Brady shared, "it's difficult to know how COVID-19 will impact coach employment, and this makes it difficult to plan resourcing needs of future online coaching programs and activities next academic year." A. Brady expressed concerns about a longer-term effect of such a downturn for universities where, because of reduced funding and work opportunities for coaches, fewer paid positions will exist. Thus, most "coaches simply cannot afford to invest in expensive degree programs and may choose free webinars or pop-up higher education courses."

\section{Personal and Professional Development}

One of the benefits realized from the pandemic that we have noted is that coaches have reported more time for personal and professional development. As M. Wilkie observed, "with our professional players placed on remote strength and 
conditioning training programs, rugby coaches have had more time to focus upon personal and professional development." Similarly, C. Kiosoglous recognized how professional rowing coaches had become "suddenly enthused and eager to undertake professional development and continual learning." The rapid increase in demand for coach development has placed considerable strain on CDs. As M. Wilkie explained, despite seeing "this demand as a real silver lining of the current situation, we have also seen our own workload magnified. I am one person servicing approximately 45 coaches during this period-and this has been tough."

As CDs, we too have had increased opportunities to engage in online learning through webinars, meetings, and courses. B. Callary noted the increased communication between practitioners and researchers, each seeking counsel, ideas, and knowledge from one another. This exchange has the potential to build a research-to-practice bridge from which we can all benefit. Furthermore, C. Kiosoglous said, "the COVID-19 lockdown, in some ways, created an opportunity to reconsider my role as a coach and coach developer as a global citizen and helped to expand my sense of what was already an existing community of practice." In turn, their reflections demonstrate the increased attention that we have placed on our CoP.

The ability to share information and discuss strategies with a diverse group within our field has enabled critical reflection and analytic thinking. "As we are a global, cross sport group, I have also found value in receiving updates from sports and countries that are more advanced in their return to train and play protocols then we are," C. Kiosoglous said. We have also been able to share and circulate online learning opportunities for coaches, which M. Wilkie noted, "has been valuable, as this is a time-efficient way to increase a learning library that I can make available to our Irish Rugby coaches.” R. Horvath acknowledged,

I have learned about how the pandemic situation is for NCDA cohort 5 members, how it is dealt with by coach developers in other parts of the world, at what stage it is and what regulations are followed, how the situation is changing, what effect it has on life, on coaches, on education, and how the restart of sport has meaning in various countries.

Our CoP has become a valued weekly gathering, and it has brought into sharper focus many shared imperatives, regardless of our organizational alignment. As we all acknowledged, we gain so much from hearing others' perspectives. P. Clewer said, "it has been useful to share ideas, tools, booklists. Most importantly, I have had an opportunity to talk about the situation with people that I really trust and who can examine the pandemic the same way as I do." R. Resende referred to the importance of being able to share one's work and empathize with group members, which "led to optimal conditions for us to all grow together." B. Callary stated, "This CoP provides the reflective space to listen to others, reorient my own lifeworld, think through problems from different perspectives, invite dialog, and this all makes me a better coach developer and a better researcher of coach development." C. Kiosoglous agreed:

Being in the group during COVID-19 [sic] has been of immense value. It gave me a sense of grounding and a calibration to all that was going on around the 
world. I realized that the global experience was quite different to what I am experiencing in the U.S. Someone had mentioned that it is like we are all in the same "storm," just in different boats, and that is an analogy I felt helped me in gaining perspective of the importance of our conversations during this period.

T. Mehrtens noted,

There has been huge benefit in testing ideas and receiving feedback weekly, as during such an ever-changing time, moving quickly but also strategically has been critical. To have such a highly skilled and knowledgeable group of people to not only test your work with, but to hear their ideas and initiatives as well, has added strength to what we have implemented at Netball NZ.

R. Resende summarized the benefits:

We have planned, acted, and reflected on our work. We are positive with one another. As a result, I have been able to change the way I do my work now. I think I'm much better professionally as a coach developer and as a researcher, but also as a person as well. The group has shown respect and confidence in each other to remain in contact every week to gain a global understanding of our field. We are building a global community of practice, which is an exceptional opportunity.

\section{Final Comments}

This account highlights the experiences of a coach developer CoP during the COVID-19 pandemic. We recognized that we were well placed to support coaches and other organizations in the transition to online learning through our experience of this modality. A surge in the uptake by coaches of online learning and development opportunities was significant, and while viewed as a silver lining in the present circumstances, this uptake resulted in a considerable increase in the workload for CDs. Understanding the impact of this additional workload poses a challenge for CDs and the organizations for whom they work to establish new and sustainable norms for working online and from home.

We learned far more about the personal lives of coaches as we worked to support them in establishing harmony between work and home life challenges. We felt strongly that, as CDs, we should model holistic care to coaches who, in turn, can embrace this with their athletes. A question we have pondered is the following: will our engagement with care and support for coaches stay with us in the return to sport, or will we slip back to prior preoccupations with the functional and technical aspects of sport? In this respect, we may have an opportunity to reimagine what sport looks like for when we return to play. Linking directly to COVID-19 and its ramifications, we may find we are presented with new problems relating to supporting physical and mental health. Thus, an imperative is to recognize the evolving domains of knowledge that both coaches and CDs may need to support the learning and well-being of those we work with. When we do return to play, how will we support coaches during conditions of potential financial instability and a precarious landscape for sport to reestablish itself?

While opportunities to access online coach education resources are rapidly increasing, which is to be applauded in many ways, it is important to ensure that 
coaches have access to quality online experiences comprised of a range of activities, including interactive sessions, to avoid the risk of relegating coach education to a passive observation of the online experience. Our experience of sharing coaches' engagement, challenges, and feedback about online learning during COVID-19 has highlighted two broad imperatives for us as a group. First, there is a need to formally evaluate how our coaches are experiencing online coach development so we can learn how to improve what we are doing. Second, there is a need to contribute to the profession to address the current lack of published literature on the topic of successful online coach education.

The challenge to CDs is to promote the value of interactive sessions and activities that connect people in meaningful ways and which will support the development of intrapersonal and interpersonal skill development. This highlights the importance of creating and accessing a group of trusted and respected peers. What has become quite apparent for us as CDs is the need to continue to develop our own awareness of coaches' ongoing and changing needs in an effort to provide appropriate support. This has repercussions for us, as professionals, for cultivating new skill sets in a dynamic and complex learning environment. In our experience, an invaluable way of supporting learning has been in our CoP.

Coaching and coach development are relationally based, and social distancing and lockdowns prevent such relationship building. During a time of fear and isolation, a notable change in coach development appears to be a heightened mutual regard for the well-being and welfare among people, in this case, coaches and CDs. Likewise, we noted that, as a microcosm of the landscape for coach development globally, the greatest success of our $\mathrm{CoP}$ is in talking honestly and openly, respecting one another, and building friendships. In sharing our personal and professional development challenges and solutions through this commentary, we noted how similar our present challenges are, and also the ways in which we may help each other.

In this commentary, eight CDs worked together to share their perspectives from different countries, with different job expectations, but all with the same goal of making meaning of how the COVID-19 pandemic has changed the way we think about and work in coach development. Through a discussion of themes, we have addressed the core questions of how the pandemic has impacted our delivery of coach education, how we dealt with emerging issues, and how we recognized the value of our $\mathrm{CoP}$ for personal and professional development. Coaching associations across the world are grappling with how to best serve their clientele, how to best develop coaches, and how to move through and out of this current lockdown position with innovative and effective strategies for coach development. Our CoP gained insight into the common issues and novel solutions in our current situation.

\section{References}

Bissett, J.E., Kroshus, E., \& Hebard, S. (2020). Determining the role of sport coaches in promoting athlete mental health: A narrative review and Delphi approach. BMJ Open Sport \& Exercise Medicine, 6(1), e000676. doi:10.1136/bmjsem-2019-000676

Braun, V., \& Clarke, V. (2006). Using thematic analysis in psychology. Qualitative Research in Psychology, 3(2), 77-101. doi:10.1191/1478088706qp063oa. 
Dohsten, J., Barker-Ruchti, N., \& Lindgren, E.C. (2020). Caring as sustainable coaching in elite athletics: Benefits and challenges. Sports Coaching Review, 9(1), 48-70. doi:10. 1080/21640629.2018.1558896

Driska, A., \& Nalepa, J. (2020). Self-paced online learning to develop novice, entry-level, and volunteer coaches. In B. Callary \& B. Gearity (Eds.), Coach education and development in sport: Instructional strategies (pp. 166-177). London, UK: Routledge.

International Council for Coaching Excellence. (2014). International Coach Developer Framework, Version 1.1. Leeds, UK: Leeds Beckett University.

Nippon Sport Science University. (2018). NCDA welcome booklet 2018-2019. Tokyo, Japan: NSSU Coach Developer Academy.

Nippon Sport Science University. (2020). Home of the NCDA. Retrieved from https://www. ncda.tokyo

Scottish Football Association. (2020, May 20). Scottish FA to educate coaching network on importance of mental health. Retrieved from https://www.scottishfa.co.uk/news/ scottish-fa-to-educate-coaching-network-on-importance-of-mental-health/

Walters, S., Rogers, A., \& Oldham, A. (2020). A competency-based approach to coach learning: The sport New Zealand coach developer program. In B. Callary \& B. Gearity (Eds.), Coach education and development in sport: Instructional strategies (pp. 154165). London, UK: Routledge.

Wenger, E., McDermott, R.A., \& Snyder, W. (2002). Cultivating communities of practice: A guide to managing knowledge. Boston, MA: Harvard Business School Press.

Wenger-Trayner, B., \& Wenger-Trayner, E. (2015). Systems conveners in complex landscapes. In E. Wenger-Trayner, M. Fenton-O'Creevy, S. Hutchinson, C. Kubiak, \& B. Wenger-Trayner (Eds.), Learning in landscapes of practice: Boundaries, identity, and knowledgeability in practice-based learning (pp. 99-118). New York, NY: Routledge. 